Бессараб Геннадий Александрович - профессор кафедры Промышленного транспорта ФГБОУ ВПО «Санкт-Петербургский государственный лесотехнический университет имени С.М.Кирова», кандидат технических наук, доцент, г. Санкт-Петербург, Российская Федерация; e-mail: vtkglta@mail.ru.

Information about authors

ArtemyevVladislavVladimirovich - Senior teacher of Industrial transport department of Federal State Budget Education Institution of Higher Professional Education «Saint-Petersburg State Forest Technical University under name of S.M.Kirov», Saint-Petersburg, Russian Federation; e-mail: artemev.vladislav@gmail.com.

Bessarab Gennady Aleksandrovich - Associate Professor of Industrial transport department of Federal State Budget Education Institution of Higher Professional Education «Saint-Petersburg State Forest Technical University under name of S.M.Kirov», Ph.D. in Engineering, Associate Professor, Saint-Petersburg, Russian Federation; e-mail: vtkglta@mail.ru.

DOI:

УДК $630 * 383$

МЕХАНИЗМ ОБРАЗОВАНИЯ МОРОЗОБОЙНЫХ ТРЕЩИН НА АВТОМОБИЛЬНЫХ ДОРОГАХ, ЭКСПЛУ АТИРУЕМЫХ В УМЕРЕННО-КОНТИНЕНТАЛЬНОМ КЛИМАТЕ доктор технических наук, профессор О. Н. Бурмистрова ${ }^{1}$ кандидат технических наук, доцент А. М. Бургонутдинов ${ }^{2}$ кандидат технических наук Ю. Н. Пильник ${ }^{1}$

1 - ФГБОУ ВПО «Ухтинский государственный технический университет», г. Ухта, Российская Федерация 2 - ФГБОУ ВО «Пермский национальный исследовательский политехнический университет», г. Пермь, Российская Федерация

Дорога - это единый инженерный комплекс, все элементы в нем работают как единое целое в тесной взаимосвязи. Надёжным фундаментом дорожной одежды является земляное полотно, которое обеспечивает её долговечность и прочность независимо от климатических, грунтовых и ряда других факторов. Возводится земляное полотно на грунтовом слое, который свои свойства изменяет в разные периоды года. Изменения могут происходить из-за воздействия природных факторов, таких как температуры воздуха и влажности грунта. Следовательно, срок службы дорожной конструкции зависит от состояния грунта, расположенного в основании дороги, его вида и влажности. В теплый период года сезонномерзлый слой постепенно полностью оттаивает и такое состояние с положительной среднегодовой температурой наружного воздуха характерно приблизительно 50 \% территории России. Промерзание влажных дисперсных грунтов сопровождается рядом физических, физико-химических и физико-механических явлений и процессов. В грунтах при замерзании воды резко и скачкообразно изменяются свойства самих грунтов, и значительно увеличивается объем мерзлого грунта, причем, не равномерно. Выявлено, что при замерзании могут возникать такие условия, при которых увеличение объема грунта вследствие миграции влаги к фронту промерзания и ее замерзания могут достигать десятков процентов. Этот процесс принято называть морозным пучением грунтов. Явление это относится к физико-механическим процессам, в результате которого под действием термодинамических изменений промерзающий грунт приобретает напряженно-деформированное состояние. Среди всего многообразия грунтов, с которыми приходится иметь дело дорожным строителям, особые затруднения вызывают структурно-неустойчивые грунты, у которых в обычных условиях, но при некоторых добавочных физических и природно-климатических воздействиях, резко нарушается структура, что обусловливает значительное ухудшение физико-механических свойств, увеличение осадок, уменьшение несущей способности, оползней склонов, прогибы дорожного полотна и т.д.

Ключевые слова: асфальтобетон, земляное полотно, теплофизические характеристики дорожных материалов, промерзание грунта, дорожная одежда, предел прочности, давление, автопоезд, морозное пучение, лесовозная дорога, льдовыделение. 


\title{
MECHANISM OF FORMATION OF FROST CRACKS ON HIGHWAYS, OPERATED IN TEMPERATE CONTINENTAL CLIMATE
}

\author{
DSc in Engineering, Professor O. N. Burmistrova ${ }^{1}$ \\ Ph.D. in Engineering, Associate Professor A. M. Burgonutdinov ${ }^{2}$ \\ $\mathrm{PhD}$ in Engineering Yu. N. Pilnik ${ }^{1}$ \\ 1 - Federal State Budget Education Institution of Higher Professional Education «Ukhta State Technical University», \\ Ukhta, Russian Federation \\ 2 - Federal State Budget Education Institution of Higher Education «Perm National Research Polytechnic University», \\ Perm, Russian Federation
}

\begin{abstract}
The road is a uniform engineering complex, all elements in it work as single entity in close interrelation. The reliable base of road clothes is the road bed which provides its durability and strength irrespectively to climatic, soil and some other factors. The road bed is constructed on a soil layer which changes the properties during the different periods of year. Changes can happen because of influence of natural factors, such as air temperature and humidity of soil. Therefore, service life of road construction depends on a condition of the soil located in foundation of the road, its type and humidity. During the warm period of year the season frozen layer gradually completely thaws and such state with a positive average annual temperature of external air is characteristic of about $50 \%$ of the territory of Russia. Frost penetration in damp disperse soil is followed by a number of the physical, physical and chemical and physical and mechanical phenomena and processes. In soil when freezing water properties of soil change sharply and in steps, and the volume of frozen soil unevenly considerably increases. It is revealed that when freezing there can be such conditions under which increase in volume of soil owing to migration of moisture to the front of frost penetration and its freezing can reach tens of percent. It is accepted to call this process as frosty action of soil. This phenomenon refers to the physical and mechanical processes, which resulted in changes under the influence of thermodynamic freezing soil becomes stress-strain state. Among the variety of soils, which road builders have to deal with, the special difficulties are caused by structurally unstable soils, in which under normal conditions, but under some additional physical and climatic influences, the structure greatly disturbed that causes significant deterioration of physical and mechanical properties, increase sediment, reducing the loadbearing capacity, landslide slopes, deflections of the roadway, etc.
\end{abstract}

Keywords: asphalt concrete, roadbed, thermal and physical characteristics of road materials, freezing of soil, pavement, tensile strength, pressure, trailer, frosty action, forest roads, ice release

Сезоннопромерзающие грунты - это весьма сложное природное многофазовое образование, состоящее из различных по свойствам компонентов, находящихся в разном фазовом состоянии. Лёд является обязательным компонентом сезоннопромерзающих грунтов.

Промерзание и оттаивание дисперсных грунтов являются основными процессами и связаны с превращениями энергии и вещества в объёме породы. Рассмотрение этих превращений проводится на базе основных положений термодинамики и теплофизики, исследуются параметры внугреннего и внешнего энергообмена (теплообмена) в промерзающих и оттаивающих системах. Данные об исследованиях влияния природных факторов на долговечность автомобильных дорог показывают, что доля дефекта колеблется от 40$80 \%$ от общего количества деформаций покрытия.
Благодаря своему граничному положению между атмосферой и нижележащими слоями сезонного промерзания и оттаивания грунтов земляного полотна верхний слой покрытия из асфальтобетона являются наиболее термодинамически активным слоем. В нём происходят интенсивные процессы тепло-массообмена, вызванные резкими изменениями температур в переходный период и солнечным зимним днём, фазовыми превращениями воды, существенными изменениями влажности особенно на участках перехода из выемки в насыпь в годовом цикле и при многолетней эксплуатации автомобильной дороги.

Известно [6], что основными источниками внешнего энергетического воздействия на земную поверхность является: лучистая энергия Солнца и звёзд; корпускулярное излучение горячих космических тел; гравитационные воздействия космических тел, сезон- 
ные и суточные колебания температуры, атмосферные осадки и др. Энергия, приобретаемая поверхностью автомобильной дороги с усовершенствованным типом покрытия за счет внешних источников, может быть рассчитана по разности между коротковолновой радиацией, поглощаемой поверхностью, и длинноволновым эффективным излучением земной поверхности, именуемой радиационным балансом подстилающей поверхности Земли $(R)$.

Приобретаемая асфальтобетонным покрытием дороги, энергия трансформируется в тепловую и расходуется на турбулентный теплообмен с атмосферой $(P)$, на испарение влаги с поверхности дорожной конструкции в атмосферу, произведение скрытой теплоты испарения - $(L)$ на количество испарившейся влаги $(E)$ и на теплообмен с подстилающими слоями дорожной одежды $(B)$. Уравнение радиационно-теплового баланса подстилающей поверхности за определенный промежуток времени может быть представлено в виде

$$
R=P+L E+B,
$$

Передачи тепла от поверхности асфальтобетонного покрытия в нижележащие слои дорожной одежды и наоборот осуществляется главным образом с помощью кондуктивного, т.е. молекулярного переноса тепла в однородных сплошных средах, реализующийся за счет теплопроводности дорожно-строительных материалов и конвективного механизмов (передача тепла осуществляется веществом, которое перемещается по порам, пустотам, трещинам путем конвекции воды, газов, водяного пара и др.). За счет конвекции теплоперенос в естественных условиях оказывается ощутимым при фильтрации свободной воды по порам и трещинам в дорожной конструкции.

Основным законом, описывающим кондуктивный перенос тепла в скальных и дисперсных породах, служит закон Фурье, который для установившегося теплового потока $Q$ записывается

$$
Q=-\lambda \cdot \operatorname{grad}(t),
$$

где $\lambda=a \cdot C_{\text {уд }} \cdot \gamma_{\text {ск }}$ - коэффициент теплопроводности,

$a$ - коэффициент температуропроводности,

$C_{\text {уд }}$ - удельная теплоемкости,

$\gamma_{\text {ск }}$ - плотность скелета грунта.

При отсутствии внутренних источников тепла в однородной системе одномерное температурное поле по глубине $x$ и во времени $\tau$ описывается уравнением теплопроводности

$$
\partial t(x, \tau) / \partial \tau=\alpha \cdot \partial^{2} t / \partial x^{2},
$$

По результатам экспериментальных исследований следует, что рост трещины на участках перехода из насыпи в выемку и разуплотнение материалов дорожной конструкции имеют место большей частью при изменении температуры и воздействию динамической нагрузки от пневматических колес автомобиля. Полученные данные свидетельствуют о том, что деформации разуплотнения рабочего слоя дорожной конструкции начинают развиваться при формировании в толще грунта земляного полотна, трещин преимущественно наклонной и горизонтальной ориентациями.

В связи с тем, что на автомобильных дорогах имеются выемки с грунтом, находящими в естественном состоянии и насыпи с грунтом нарушенной структуры, на участках сопряжений происходят необратимые процессы, приводящие к появлению трещин.

В результате лабораторных исследований было установлено, что температура начала замерзания грунта насыпи составляет $0{ }^{0} \mathrm{C}$, а в выемке - минус $0,5{ }^{0} \mathrm{C}$ [5]. Процесс сезонного промерзания и оттаивания дорожной конструкции в местах сопряжения насыпи с выемкой приводит к неравномерной усадке данных участков и появлению поперечных трещин с различным шагом.

При одинаковой влажности и плотности грунта насыпи и выемки коэффициент теплопроводности для грунта выемки в 1,5 раза выше, чем грунта насыпи. Этим объясняется существенное различие в термическом режиме связных природных и с нарушенной структурой грунтов при равной плотности. Весной и летом грунт насыпи интенсивнее нагревается, а охлаждается быстрее осенью и зимой. Следовательно, на коэффициентах переноса тепла существенно сказывается наличие или отсутствие жёстких структурных связей между частицами глинистого грунта. В данном случае передача тепла в грунте выемки осуществляется от частицы к частице через жесткие связи, а в насыпи через плёнки связной воды обволакивающие глинистые частицы. Но теплопроводность материала скелета выше тепловодности воды и поэтому коэффициенты температуропроводности и теплопроводности для природного грунта выемки всегда выше, чем грунта насыпи с нарушенной структурой равной плотности. Таким образом, на участках сопряжения грунта с нарушенной структурой и находящего в естественном состоянии распространения тепла и влаги в природном грунте 
происходит быстрее, чем в грунте с нарушенной структурой. Причём, в глинистых грунтах скорость распространения потенциалов влаги ниже скорости распространения потенциалов тепла. Следовательно, в грунтах с нарушенной структурой относительная скорость распространения влаги по отношению к скорости распространения тепла выше, чем в природном грунте.

Как было доказано советским учёным В.И. Фёдоровым, что коэффициент теплопроводности грунта увеличивается по мере роста плотности и влажности последнего [7]. Однако при влажности грунта нарушенной структуры равной $33 \%$ его коэффициент температуро-проводности остается ниже, чем у грунта с ненарушенной структурой, имеющему влажность 28 \%. Коэффициент влагопроводности у естественного (ненарушенной структуры) грунта всегда в 1,22 раза выше, чем у грунта с нарушенной структурой.

Задача о протекании процесса образования морозобойной трещины - это сложная задача математической физики. Основной трудностью решения этой задачи является учёт изменения агрегатного состояния и теплофизических характеристик среды. В результате задача приобретает нелинейный характер. Кроме того, при промерзании и оттаивании одновременно с изменением температурного поля имеет место массоперенос, вызванный перемещением влаги в дорожной конструкции.

Перемещение воды в жидком и парообразном виде имеет место преимущественно в промерзающих грунтах, т.е. в умеренно-континентальном климате.

Условия перемещения влаги в глинистых грунтах на территории Пермского края отличаются от условий передвижения её в немерзлых грунтах: во-первых, в замерзающих слоях дорожной одежды под асфальтобетонным покрытием пары воды не только конденсируются в жидкость, но и превращаются непосредственно в лёд, увеличивая льдистость грунта земляного полотна у фронта промерзания; во-вторых, миграция паров может происходить и при одной и той же температуре, т.к. упругость паров льда меньше упругости паров воды. Существенный вклад в описании данных процессов был внесен российским ученым Н. А. Цытовичем [8]. Использование результатов экспериментальнотеоретических исследований ведущих ученых мира в дальнейшем были использованы в дорожном, промьшленном и гражданском строительстве [9].
Согласно проведённым нами экспериментальным исследованиям на границе соприкосновения природного грунта и грунтом с нарушенной структурой существует скачёк влажности глинистого грунта [5]. Для случая связного переноса влаги в местах сопряжения насыпи с выемкой на основании уравнения Лапласа (6) получим систему двух дифференциальных уравнений, для грунта выемки (ненарушенная структура) и грунта насыпи с нарушенной структурой, уплотнённого до коэффициента уплотнения равной

$$
\frac{\partial \theta}{\partial \tau}=k \nabla^{2} \theta+k \frac{\delta}{c_{m}} \nabla^{2} t,
$$

Для грунта выемки выражение будет иметь вид

$$
\begin{aligned}
& \frac{\partial^{2} \theta(x, z, \tau)}{\partial \tau}=k\left(\frac{\partial^{2} \theta(x, z, \tau)}{\partial x^{2}}+\frac{\partial^{2} \theta(x, z, \tau)}{\partial z^{2}}\right)+ \\
& +k \frac{\delta}{c_{m}}\left(\frac{\partial^{2} t(x, z, \tau)}{\partial x^{2}}+\frac{\partial^{2} t(x, z, \tau)}{\partial z^{2}}\right),
\end{aligned}
$$

Для уплотнённого грунта насыпи

$$
\begin{aligned}
& \frac{\partial^{2} \theta^{\prime}(x, z, \tau)}{\partial \tau}=k^{\prime}\left(\frac{\partial^{2} \theta^{\prime}(x, z, \tau)}{\partial x^{2}}+\frac{\partial^{2} \theta^{\prime}(x, z, \tau)}{\partial z^{2}}\right)+ \\
& +k^{\prime} \frac{\delta^{\prime}}{c_{m}^{\prime}}\left(\frac{\partial^{2} t^{\prime}(x, z, \tau)}{\partial x^{2}}+\frac{\partial^{2} t^{\prime}(x, z, \tau)}{\partial z^{2}}\right),
\end{aligned}
$$

Условие стационарного влагообмена на границе сопряжения выемки с насыпью будет иметь следующий вид

$$
\begin{aligned}
& k \cdot c_{m} \cdot \rho_{d}\left(\frac{\partial \theta(o, z, \tau)}{\partial x}\right)= \\
& =k^{\prime} \cdot c_{m}^{\prime} \cdot \rho_{d}^{\prime}\left(\frac{\partial \theta^{\prime}(o, z, \tau)}{\partial x}\right)
\end{aligned}
$$

Дифференциальные уравнения, которые были получены, позволяют математически объяснить причину образования морозобойных трещин на асфальтобетонном покрытии автомобильных дорог и дают возможность проанализировать процессы влагонакопления, выяснить взаимную связь между процессами и определить мероприятия по ликвидацию причины образования морозобойной трещины в нулевых отметках автомобильных дорог.

Таким образом, в отношении тепловых свойств глинистого грунта рабочего слоя следует рассматривать выемку и насыпь как два различных физических тела, существенно отличающихся друг от друга по своим свойствам. 


\section{Библиографический список}

1. Michalowski, R.L. Frost heave modeling using porosity rate function [Text] / R.L. Michalowski, Z. Ming // International journal for numerical and analytical methods in geomechanics. - 2006. - pp. 703-722.

2. Michalowski, R.L. Modeling of freezing in frost-susceptible soils [Text] / R.L. Michalowski, Z. Ming // Computer assisted mechanics and engineering science. - 2006. - pp. 613-625.

3. Omelyanov, G.A. Interaction of Free Boundaries in the Modified Stefan Problem, Nonlinear [Text] / G.A. Omelyanov, V.Yu. Rudnev // Phenomena in Complex Systems. - 2004. - pp. 227-237.

4. Selvadurai, A.P.S. Computational modeling of frost heave induced soil-pipeline interaction: Modeling of frost heaving [Text] / A.P.S. Selvadurai, J. Hu, I. Konu // Cold regions science and technology. - 1999. - pp. 215-228.

5. Бургонутдинов, А.М. Обоснование способов строительства и ремонта лесовозных автомобильных дорог, препятствующих образованию трещин (на примере Пермского края) [Текст] : дисс. ...канд. техн. наук / А.М. Бургонутдинов. - Йошкар-Ола: МарГТУ, 2012.

6. Бургонутдинов, А.М. Учёт образования морозобойных трещин при строительстве трубопроводов [Текст] / А.М. Бургонутдинов, Б.С. Юшков // Защита окружающей среды в нефтегазовом комплексе. - М.: Издво МНИТС, 2011. - № 7. - С. 39-43.

7. Бургонутдинов, А.М. Электрохимическое закрепление глинистых грунтов при борьбе с морозными трещинами на автомобильных дорогах [Текст] / А.М. Бургонутдинов, О.Н. Бурмистрова, Б.С. Юшков // Фундаментальные исследования. - 2014. - № 9. - Ч. 6. - С. 2019-2028.

8. Савельев, В.В. Обоснование типа и конструкций одежд лесовозных автомобильных дорог [Текст]: дис. ... д-ра техн. наук / В.В. Савельев. - Йошкар-Ола, 2006. - 516 с. - С. 296-319.

9. Ершов, Э.Д. Влагоперенос и криогенные текстуры в дисперсных породах [Текст] / Э.Д. Ершов. - М.: Изд-во МГУ, 1979. - 213 с.

10. Жинкин, Г.Н. Электрохимическая обработка глинистых грунтов в основаниях сооружений [Текст] / Г.Н. Жинкин. - М.: Стройиздат, 1980. - 164 с.

11. Воронкевич, С.Д. Физико-химические процессы техногенной эволюции грунтов. [Текст] / С.Д. Воронкевич, Н.А. Ларионова. - М.:МГУ, 2000.

12. Федоров, В.И. Процессы влагонакопления и морозоопасность грунтов в строительстве. [Текст] / В.И. Федоров. - Владивосток, 1992.

13. Цытович, Н.А. Механика мерзлых пород [Текст] / Н.А. Цытович. - М.: Высшая школа, 1973.

14. Юшков, Б.С. Экспериментально-теоретические основы расчета фундаментов из двухконусных свай, устраиваемых в сезоннопромерзающих грунтах [Текст] / Б.С. Юшков. - Пермь: Изд-во «ОТ и ДО», 2015.

\section{References}

1. Michalowski R.L., Ming Z. Frost heave modeling using porosity rate function. International journal for numerical and analytical methods in geomechanics, 2006, pp. 703-722.

2. Michalowski R.L., Ming Z. Modeling of freezing in frost-susceptible soils. Computer assisted mechanics and engineering science, 2006, pp. 613-625.

3. Omelyanov G.A., Rudnev V.Yu. Interaction of Free Boundaries in the Modified Stefan Problem, Nonlinear Phenomena in Complex Systems, 2004, pp. 227-237.

4. Selvadurai A.P.S., Hu J., Konu I. Computational modeling of frost heave induced soil-pipeline interaction: Modeling of frost heaving. Cold regions science and technology, 1999, pp. 215-228.

5. Burgonutdinov A.M. Obosnovanie sposobov stroitel'stva i remonta lesovoznyh avtomobil'nyh dorog, prepjatstvujushhih obrazovaniju treshhin (na primere Permskogo kraja) Diss. kand. tehn. nauk [Substantiation of ways of building and repair lesovoznyh to-horn, preventing the formation of cracks (on the example of the Perm region) Diss. $\mathrm{PhD}$ in Engineering]. Yoshkar-Ola, 2012. (In Russian).

6. Burgonutdinov A.M., Jushkov B.S. Uchjot obrazovanija morozobojnyh treshhin pri stroitel'stve truboprovo- 
dov [Accounting Education frost cracks in the construction of pipelines] Zashhita okruzhajushhej sredy v neftegazovom komplekse [Environmental protection in oil and gas sector]. Moscow, 2011, no. 7, pp. 39-43. (In Russian).

7. Burgonutdinov A.M., Burmistrova O.N., Jushkov B.S. Jelektrohimicheskoe zakreplenie glinistyh gruntov pri bor'be s moroznymi treshhinami na avtomobil'nyh dorogah [Electrochemical consolidation of clay soils in the fight against frost cracks on highways] Fundamental'nye issledovanija [Fundamental research]. 2014, no. 9, Issue 6, pp. 2019-2028. (In Russian).

8. Saveliev V.V. Obosnovanie tipa i konstrukcij odezhd lesovoznyh avtomobil'nyh dorog Dis. d-ra tehn. nauk [Substantiation of type and designs clothes of forest roads dis DSc in Engineering]. Yoshkar-Ola, 2006, 516 p, pp. 296 319. (In Russian).

9. Ershov E.D. Vlagoperenos i kriogennye tekstury v dispersnyh porodah [Moisture transfer and cryogenic textures in dispersed rocks]. Moscow, 1979, pp. 213. (In Russian).

10. Zhinkin G.N. Jelektrohimicheskaja obrabotka glinistyh gruntov v osnovanijah sooruzhenij [Electrochemical treatment of clay soils in the foundations facilities]. Moscow, 1980, pp. 164. (In Russian).

11. Voronkevich S.D., Larionova N.A. Fiziko-himicheskie processy tehnogennoj jevoljucii gruntov [Physical and chemical processes of technological evolution of soils]. Moscow, 2000. (In Russian).

12. Fedorov V.I. Processy vlagonakoplenija i morozoopasnost' gruntov v stroitel'stve [Processes vlagonakopleniya and Frost Soil in Construction]. Vladivostok, 1992. (In Russian).

13. Tsytovich N.A. Mehanika merzlyh porod [Mechanics of permafrost]. Moscow, 1973. (In Russian).

14. Jushkov B.S. Jeksperimental'no-teoreticheskie osnovy rascheta fundamentov iz dvuhkonusnyh svaj, ustraivaemyh $v$ sezonnopromerzajushhih gruntah [Experimental and theoretical basis of the calculation of the foundations of the Cone piles, arranged in SEASONALLY soils]. Perm, 2015. (In Russian).

\section{Сведения об авторах}

Бурмистрова Ольга Николаевна - заведующая кафедрой технологии и машины лесозаготовок, ФГБОУ ВО «Ухтинский государственный технический университет», доктор технических наук, профессор, г.Ухта, Российская Федерация; e-mail: oburmistrova@ugtu.net.

Бургонутдинов Альберт Масугутович - доцент кафедры автомобильных дорог и мостов Федерального государственного бюджетного образовательного учреждения высшего образования «Пермский национальный исследовательский политехнический университет», кандидат технических наук, доцент, г. Пермь, Российская Федерация; e-mail: burgonutdinov.albert@yandex.ru

Пильник Юлия Николаевна - доцент ФГБОУ ВПО «Ухтинский государственный технический университет», кандидат технических наук, г. Ухта, Российская Федерация; e-mail: ypilnik@mail.ru.

\section{Information about authors}

Burmisrtova Olga Nikolaevna - Head of the Department of Industrial Transport, Technology and machines of timber cuttings, Federal State Budget Education Institution of Higher Professional Education «Ukhta State Technical University», DSc in Engineering, Professor, Ukhta, Russian Federation; e-mail: oburmistrova@gmail.com

Burgonutdinov Albert Masugutovich - Associate Professor of roads and bridges, Federal State Budget Education Institution of Higher Education «Perm National Research Polytechnic University», PhD in Engineering, Associate Professor, Perm, Russian Federation; e-mail: burgonutdinov.albert@yandex.ru

Pilnik Yulia Nikolaevna - Associate Professor, Federal State Budget Education Institution of Higher Professional Education «Ukhta State Technical University», PhD in Engineering, Ukhta, Russian Federation; e-mail: ypilnik@mail.ru. 